\title{
On Mechanical Characteristics of Stiffening Suspension Cable Reinforced Steel Truss Bridge
}

\author{
X.B. SU, S.H. GONG \& J.N. SU \\ China Merchants Chongqing Communications Technology Research \& Design Institute Co. LTD
}

KEYWORD: Stiffening Suspension Cable; Steel Truss Beam; Mechanical Characteristics; Mechanical Law Chinese library classification number.

ABSTRACT: Space plate-beam mixed unit model is established. Mechanical characteristics of a stiffening suspension cable reinforced steel truss bridge is analyzed preliminarily. The mechanical principles of the bridge type are discussed through studying the influence of stiffening suspension cable vector height, length and suspender rigidity change on structure force.

\section{INTRODUCTION}

Stiffening suspension cable reinforced steel truss bridge is a bridge structure, which was emerged in recent years. Since a part of advantages of self-anchored suspension bridge and variable crosssection steel truss girder are absorbed, it is characterized by low building height, artistic shape and none anchorage device. It has larger span compared with traditional steel truss girder, which has larger vertical and transverse rigidity compared with self-anchored suspension bridge. Therefore, the bridge has certain competitiveness in bridge structure with medium span. However, since the bridge has novel structure, it has mechanical characteristics of suspension bridge and variable cross-section steel truss girder. The stiffening suspension cable and main beams are connected through rigid boom locally. It is completely different from traditional suspension bridge. There must be difference in force transmission mechanism and mechanical characteristics [1]. It is also different from variable cross-section steel continuous trussed girder bridge in traditional significance. Mastering of mechanical characteristics and mechanics laws of the bridge is beneficial for guiding engineering practice better. In the paper, the aspect is explored preliminarily.

\section{PROJECT SUMMARY}

A stiffening suspension cable reinforced steel truss bridge is provided with orthotropic steel bridge panel girder combination structure. The span layout is $135+270+135 \mathrm{~m}$. The girder is provided with double-layer deck. Six-lane urban main road is arranged on the upper layer. Two-way light rail is arranged on the lower layer. A triangle truss with vertical member is adopted for main truss. The standard truss is $13.5 \mathrm{~m}$ high. The steel stiffening suspension cable is as high as $28 \mathrm{~m}$ on main pier bearing. Circular curve with the radium of $180 \mathrm{~m}$ is adopted for the design line type. They extend to main span and side span for $74 \mathrm{~m}$ respectively, which are crossed on the major node of top boom. Two main girders are adopted transversely with center distance of $26.2 \mathrm{~m}$. The whole bridge is designed into overall nodes in order to facilitate processing and installation, and save bolt quantity. The schematic diagram of bridge structure is shown in Figure 1.

\section{CALCULATION METHODS}

There are common calculation methods of plate truss composite structures: simplified plane beam element method, spatial plate - beam combination method and plate casing unit [2]. Effective width description bridge panel is adopted in plane beam element method to participate in chord stress. It is a kind of approximate processing. Its calculation precision is closely related to calculator experience and recognition degree on structure space behavior. Plate unit simulation bridge panel is adopted in spatial plate - beam combination method. Beam unit simulation chord beam, longitudinal and transverse beam can better reflect the spatial relationship of the structure, which is closer to ac- 
tual situation. It has the defect that there are more units, thereby leading to higher expense. Mechanical condition of the structure can be reflected most accurately by plate casing unit. It has defects that the processing is complicated in front of and behind the model. The calculation expense is larger compared with two former methods. Only second system and third system are always analyzed. The above analysis is integrated. Main beam finite element model is established by adopting spatial plate - beam combination method. Corresponding boundary conditions are applied on bearing position. Since overall nodes are designed on the whole bridge. The node joints in the model undergo rigid treatment.

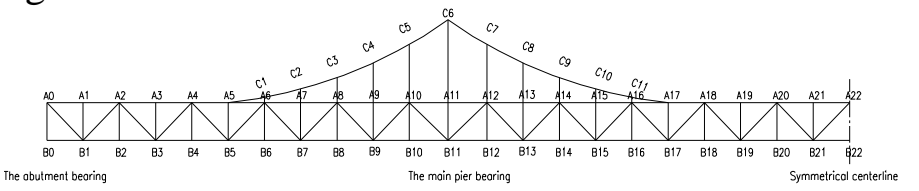

Bridge abutment; main pier bearing; symmetrical center line

Figure 1. Schematic diagram of bridge structure and node number (half-structure)

\section{MAIN MECHANICAL CHARACTERISTICS}

\section{Influence of dead loan and live loan}

The proportion of dead loan in the total loan is generally lower aiming at small span railway steel truss bridges, thereby leading to direct problem of higher live load proportion and prominent fatigue problem of bar member; the highway steel truss bridge generally has lighter live load, and its proportion is reduced greatly. In literature [3], the constant loan ratio of several steel truss bridge is listed (constant load/general load, the same as follows). It is obvious hat the fatigue problem of railway steel truss bridge is much more serious than the highway.

Table 1. List of dead loan proportion i several bridges

\begin{tabular}{ccc}
\hline Bridge name & Bridge & Dead/total; \\
\hline Sunkou Yellow River Bridge & Double-line railway steel truss & $30 \%$ \\
Changao Yellow River No. 1 Bridge & Single-line railway steel truss & $27 \%$ \\
Nangang-Daban Bridge & $\begin{array}{c}\text { Double-layer highway steel } \\
\text { truss }\end{array}$ & $82 \%$ \\
\hline
\end{tabular}

The bridge belongs to public rail dual-purpose steel truss bridge. There is no previous example for following in the aspect of dead and live load ratio. The axial stress of main bar is given under various load condition as shown in Table 2 . It is obvious that the ratio of gravity stress and dead loan stress in the bar is about $66 \%$. The internal force of about $1 / 3$ member bars is contributed by two dead loads. The dead load ratio of different member bars is different under the effect of load combination, wherein the upper chord is close to $70 \%$. The bar on the lower chord bearing is about $79 \%$, and the middle part of the span is $71 \%$. The dead load ratio of the stiffening suspension cable is relatively uniform, which is about $77 \%$. Calculation also indicates that the dead load ratio of all member bars is not more than $80 \%$. The above analysis shows that the bridge has the following characteristics: (1) the dead loan ratio of member bars is between $68 \%$ and $68 \%$, which is far more than railway steel truss, and fatigue problem is improved significantly; (2) the proportion of two dead loads is about $40 \%$ in the constant load effect. The auxiliary dead-weight can be reduced. Light structures should be adopted in pavement and rail track as far as possible. It is one of directions to optimize the bridge type. 
Table 2. List of dead and live load proportions of main member bars in the truss

\begin{tabular}{ccccccccc}
\hline & & \multicolumn{7}{c}{ Axial stress (Mpa) } \\
\cline { 3 - 9 } Part & $\begin{array}{c}\text { Member } \\
\text { bars }\end{array}$ & $\begin{array}{c}\text { Dead } \\
\text { weight }\end{array}$ & $\begin{array}{c}\text { Dead } \\
\text { loan }\end{array}$ & $\begin{array}{c}\text { Dead } \\
\text { weight/dea } \\
\text { d loan }\end{array}$ & $\begin{array}{c}\text { Automobile } \\
\text { live load }\end{array}$ & $\begin{array}{c}\text { Ligh } \\
\text { t rail } \\
\text { live } \\
\text { load }\end{array}$ & $\begin{array}{c}\text { Temperature } \\
\text { live load }\end{array}$ & $\begin{array}{c}\text { Con- } \\
\text { stant/total }\end{array}$ \\
\hline $\begin{array}{c}\text { Upper } \\
\text { chord }\end{array}$ & A11A12 & 40.4 & 60.3 & $67.0 \%$ & 5.1 & 5.1 & 17.9 & $68.2 \%$ \\
\hline $\begin{array}{c}\text { Lower } \\
\text { chord }\end{array}$ & B11B12 & -41.4 & -76.8 & $66.9 \%$ & -14.9 & -10.9 & -8.2 & $69.3 \%$ \\
\hline $\begin{array}{c}\text { Stiffening } \\
\text { suspen- } \\
\text { sion cable }\end{array}$ & C1C2 & 61.4 & -70.1 & $65.2 \%$ & -7.3 & -5.6 & -5.9 & $78.9 \%$ \\
\hline
\end{tabular}

\section{Influence of node rigidity}

Overall node has the following advantages compared with scattered node: bolts are saved, and installation is convenient. However, since its rigidity is high, prominent secondary stress problem can be caused. Studies show that the production of secondary stress is related to load action position, member bar linear rigidity, relative axial deformation and other factors [4]. Chinese specification stipulates that the ratio between main truss member bar cross section height and node length is larger than $1 / 15$ in the continuous truss girder. When the ratio is larger than $1 / 10$ in the simply supported truss girder, the secondary stress caused by node rigidity [5] should be calculated. The ratio between upper chord and lower chord cross section height of the bridge and the node length is $1 / 10.2$ and 1/8.1 respectively. Secondary stress should be considered. Meanwhile, the allowable stress of steel materials also should be improved correspondingly. However, there is not comprehensive specification about how to improve coefficient aiming at different load combinations. In actual operation, the situation is always judged according to experience of engineering personnel with stronger subjectivity. In addition, there are also other viewpoints about the secondary stress. For example, it is suggested in literature [3] that when the secondary force is undertaken by box-type member bar for larger proportion (for example more than 30\%), the allowable stress can be increased slightly, which is even not improved. It is obvious that the secondary stress issue on the truss structure still should be further studied.

The lower chord is adopted as an example for explaining the secondary stress effect of the member bars in the bridge. Comparison condition of axial stress and combination stress of lower chord is shown in figure 2 . It is obvious that the secondary stress effects are different in different parts. Secondary stress ratio (secondary stress/combination stress is the same as below, and no further information is given hereinafter) maximum value is $55.6 \%$, which is produced in B5 cross-section, which is mainly affected by overall node in $\mathrm{A} 5 \mathrm{C} 1$; the secondary stress ratio of support node B11 cross section is $43.2 \%$, which is in the second place. The secondary stress ratio of the mid-span B22 cross section is the lowest, namely $13.1 \%$. It is fully obvious that the secondary force effect of member bars is positively proportion to the rigidity. When the rigidity (including cross section rigidity and supporting rigidity) is changed suddenly, the secondary stress effect of the member bar is particularly significant. The maximum secondary stress can be even higher than the axial stress, which should be emphasized fully in design. The secondary stress level can be much reduced due to even rigidity in the mid-span area. 


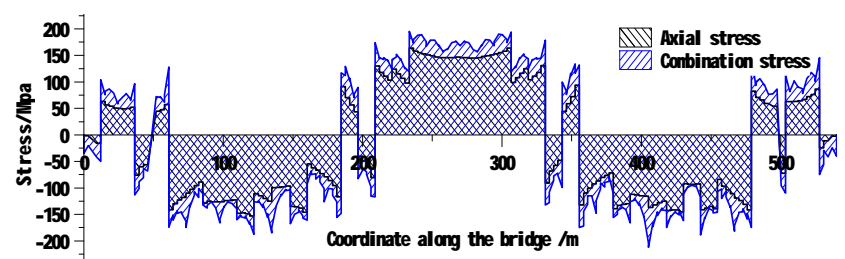

Figure 2. Comparisons between axial stress and combination stress of lower chord

\section{Mechanical characteristics of stiffening suspension cable and derrick}

Comparison of axial stress and combination stress of stiffening suspension cable is shown in figure 3 . The stiffening suspension cable belongs to tension member bar, and the maximum tensile stress is $186 \mathrm{Mpa}$, which occurs in the top C6 cross section mainly because the secondary stress effect is the most prominent in the cross section. The contribution ratio is $48.6 \%$, which is followed by two neighboring nodes C5 and C7. Secondary stress ratio is about $43 \%$. The secondary stress is reduced gradually with extension of main span and side span. The secondary stress effect should be reduced to the minimum level in the main tower node $\mathrm{C} 10$, and the secondary stress ratio is only $3 \%$.

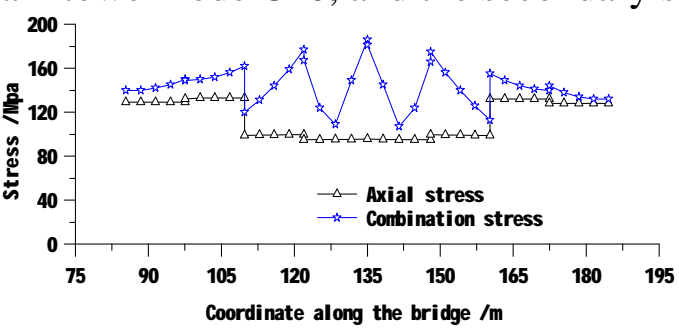

Figure 3. Comparison between axial stress and combination stress of stiffening suspension cable Figure 4 shows the comparison condition of axial stress and combination stress of stiffening suspension cable. It is obvious that (1) both the bearing and two neighboring derricks are stressed, which is different from full tension on the flexible derricks; (2) the cross section of derricks on the bearing is far bigger than other member bars, and they are main stress member bars, two stable triangle member bars are formed with stiffening suspension cable for bearing load, other derricks only play auxiliary role to improve main beam stress; (3) the secondary stress effect of the derricks is distributed in 'M' shape with the change of consequent coordinates. No secondary stress is produced basically on the derricks on the left and right ends. The secondary stress effect of two neighboring side derricks reaches the maximum value, about $78 \%$, and it is reduced gradually then. The secondary stress on the derricks in the bearing is lower, which is about $9 \%$ only.

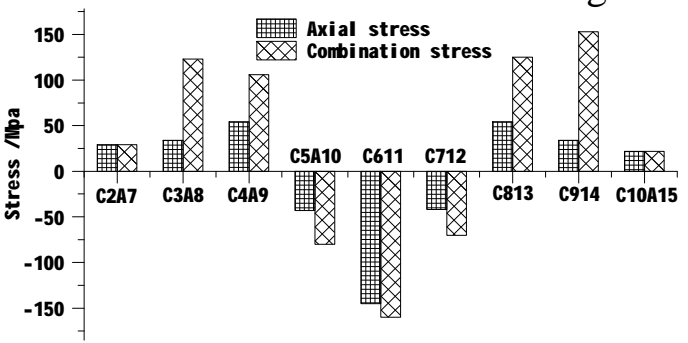

Figure 4. Comparisons between axial stress and combination stress in rigid suspender

\section{PARAMETER ANALYSIS}

The design parameters of stiffening suspension cable are adjusted. The mechanical rules of main truss member bar are studied. It has guidance role to further comprehend the mechanical characteristics of the bridge. Data support is also provided for optimization design.

\section{Influence of vector height}

The stress influence of the stiffening suspension cable on main member bars of the main truss can be analyzed through changing the vector height of the stiffening suspension cable. The (absolute) maximum stress of main member bars under different vector heights is shown in figure 5 . The vector height is increased from $10 \mathrm{~m}$ to $40 \mathrm{~m}$, and the maximum stress of stiffening suspension cable is changed between $144 \mathrm{Mpa}$ to $155 \mathrm{Mpa}$. The stress influence of vector height on the stiffening sus- 
pension cable is limited. The chord stress level is reduced with increase of vector height. The bearing part is more sensitive to the change of the vector height compared with mid-span member bars. When the vector height is increased from $10 \mathrm{~m}$ to $40 \mathrm{~m}$, the member bar stress of the upper chord bearing part is reduced from 193Mpa to 96Mpa with drop extend of about 50.3\%. The member bar stress on the lower chord bearing part is reduced from -238Mpa to $-148 \mathrm{Mpa}$, with drop extent of $37.8 \%$. The stress decrease of member bars in the upper chord and lower chord mid-span member bars is about $17 \%$. The maximum stress of diagonal web member reaches the lowest level when the stiffening suspension cable vector height is $29 \mathrm{~m}$. When the vector height is increased to $40 \mathrm{~m}$, the maximum stress is also increased slightly. The diagonal web member stress is not sensitive to the change of vector height.



Figure 5. Maximum absolute stress of member bars under different vector heights

\section{Influence of stiffening suspension cable length}

Three plans are designed for changing the extension length of stiffening suspension cable to both sides of bearing as shown in Table 3. The (absolute) maximum stress of main member bars under all plans is shown in figure 6. It is obvious that the maximum stress of stiffening suspension cable and members bars of upper chord and lower chord can be reduced with the increase of stiffening suspension cable. The decrease extent is $20 \%$ and $23 \%$ respectively. However, the maximum stress of the bearing and diagonal web member can be increased. The stress of bearing parts on the upper and lower chords is increased by $81 \%$ and $38 \%$ respectively from plan I to plan III. The diagonal web member stress is also increased by $36 \%$. The influence of bearing part member bar stress on suspension cable length is the most sensitive. The stress influence of stiffening cable length change on the diagonal web member is limited.

Table 3. Schematic diagram of three plans of stiffening suspension cable

\section{Horizontal projection}

\begin{tabular}{|c|c|c|}
\hline Plan & $\begin{array}{l}\text { Horizontal projection } \\
\text { length of stiffening suspen- } \\
\text { sion cable }\end{array}$ & Drawing \\
\hline
\end{tabular}

Plan I

Figure 6. Maximum absolute stress of member bars under different plans

\section{Rigidity of derrick rigidity}

The auxiliary derricks are designed into flexible derricks according to the derrick mechanical characteristics in section 3.3; thereby it can bear tensile force. Its influence on main beam stress is analyzed. The stress condition of main member bars under two derrick rigidity is shown in figure 7 to 
figure $9^{*}$. It is obvious that the derrick is changed from rigidity to flexibility. The stress of upper and lower chords is not changed basically. It has certain disturbance on the stress of stiffening suspension cable, wherein the maximum increase of the mid-span cross section stress can be up to $30 \%$ or so.

* The stress value under dead load effect is shown as follows in order to facilitate comparison.

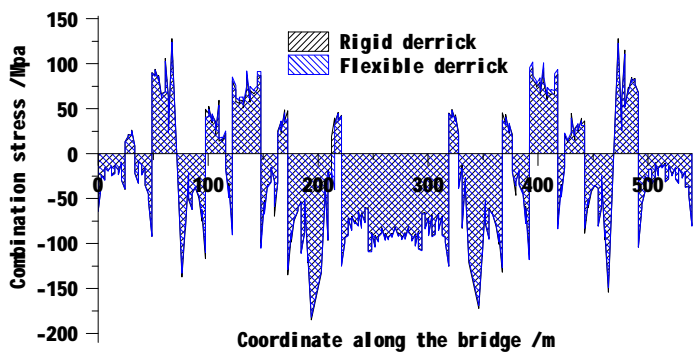

Figure 7. The dead load stress of upper chord under different derrick rigidities

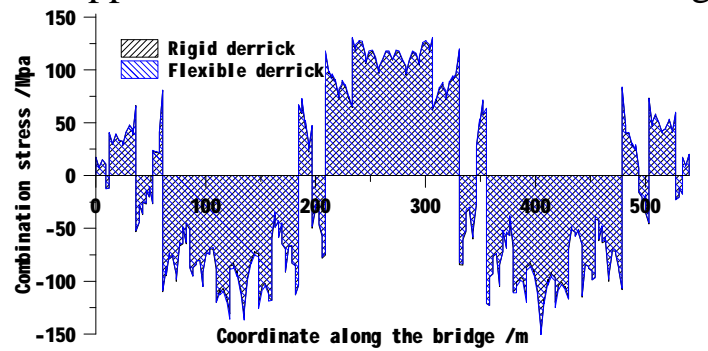

Figure 8 . The dead load stress of lower chord under different derrick rigidities

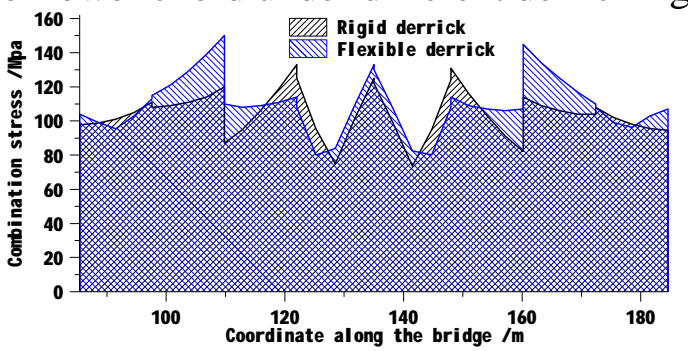

Figure 9. Dead load stress of stiffening suspension cable under different derrick rigidities

\section{CONCLUSION}

Spatial plate - beam mixing unit model of one stiffening suspension cable reinforced steel truss bridge is established. Main mechanical characteristics of the bridge are studied preliminarily, which is mainly shown as follows:

(1) The dead load ratio of member bars is between $68 \%$ and $80 \%$. The fatigue problem is improved prominently compared with railway steel truss bridge; The proportion of two dead loads is higher, weight two dead loads is reduced, light materials are used as far as possible, and it is the optimization direction of the bridge;

(2) The secondary stress effect of the member bar can not be ignored; the secondary stress proportion even can be higher than $50 \%$ in the bearing part with rigidity mutation. The secondary stress effect should be reduced prominently in the mid-span area;

(3) The stiffening suspension cable is a tensile member bar; the maximum secondary stress proportion is discovered at the top of suspension cable, which is about $49 \%$. The secondary stress proportion is reduced gradually with extension to the main span and the side span;

(4) The bearing two neighboring derricks belong to compression member bars, which is different from flexible derrick. The derricks on the bearing belong to main force derricks. It can form stable triangle component with the stiffening suspension cable, thereby improving the force on the min beam. Other derricks only play auxiliary role;

(5) The change of stiffening suspension cable vector height has limited influence on own stress of stiffening suspension cable. The stress level of the upper chord and lower chord is decreased with 
the increase of vector height. The bearing part is more sensitive to the change of vector height compared with mid-span member bars. The maximum stress decrease extent is up to 50\%;

(6) The length of stiffening suspension cable can be increased for reducing the stress of chord midspan member bars by about $20 \%$. However, the stress level of the member bars on the bearing can be maximally increased by $81 \%$. The stress increase of the diagonal web member also can be increased by $36 \%$;

(7) Rigid derrick is changed into flexible derrick, which has no influence on the stress of the chord basically. It has certain disturbance on the stress distribution of stiffening suspension cable. The stress increase extent is the maximum to the mid-span cross section, which can be up to $30 \%$ or so.

\section{REFERENCE}

[1] Zhang Junguang, Liu Yongjian, etc. Parameters Sensitivity Analysis of Steel Truss Bridge Stiffened with Rigid Cable. Journal of Zhengzhou University (Engineering Science), 2010,31(5):55-59.

[2] Tong Dengguo. Research on Mechanical Properties and Calculation Methods for Double-Truss Four-line Plate-truss Composite Continuous Steel Trusses. Chengdu, Southwest Jiaotong University, 2009.

[3] Zhao Tingheng. Design of details in bridge steel structure. Chengdu: Southwest Jiaotong University Press, 2011;

[4] Wang Fumin, etc. Design technique of super-large span steel truss arch bridge. Chongqing: Chongqing University Press, 2010;

[5] Ministry of Railways in the People's Republic of China. TB 10002.2-2005 specification for design of railway bridge steel structure. Beijing: China Railway Publishing House, 2005. 